\title{
Laparoscopic Versus Laparotomy Approach in Surgical Treatment of Endometrial Cancer: Pelvic Lymphadenectomy Results
}

\author{
Eduardo Gonzalez-Bosquet* and Carlos Lozada
}

Department of Gynecologic Surgery/Gynecologic Oncology, Sant Joan de Deu University Hospital, Barcelona, Spain

*Corresponding author: Eduardo Gonzalez Bosquet, MD, PhD, Department of Gynecologic Surgery/Gynecologic Oncology, Sant Joan de Deu University Hospital, Pg. Sant Joan de Déu, 2, 080950 Esplugues (Barcelona), Spain, Tel: 34-93-2804000, Fax: 34-93-2033959, E-mail: edugonzalez@hsjdbcn.org

\begin{abstract}
Aim: Compare the efficacy of laparoscopic versus laparotomy approach in women with early stage endometrial adenocarcinoma.

Methods: Case control retrospective study of 226 women treated of early endometrial cancer. 79 patients in the laparoscopy group and 147 in the laparotomy group. Variables analyzed in both groups were patient age, body mass index, duration of follow-up, FIGO 2009 surgical stage, tumor grade, histopathologic type, number of lymph nodes yielded, operating time, postoperative hospital admission, perioperative and postoperative complications, conversion to laparotomy, recurrence, and survival. Statistical analysis was performed using SPSS version 20.0. The Student $t$ test was used to compare the mean values of continuous variables, and the $X^{2}$ test was used to compare categorical variables.
\end{abstract}

Results: There were no significant differences in age, weight, body mass index, parity, previous abdominal surgery, number of lymph nodes yielded and menopausal status between the laparoscopy and the laparotomy groups. There were no statistically significant differences in the numbers of nodes and node metastases obtained in the laparoscopy and the laparotomy groups. The operating time was shorter in the laparotomy group. Intraoperative and postoperative complications were significant less frequent in laparoscopy group $(13.9 \%$ vs. $32.5 \%$; $P=0.003)$. Women had a similar 5 years estimated recurrence-free survival (98\% in laparoscopy vs. 94\% laparotomy group) and similar 5 years overall survival rates (100\% in laparoscopy vs. $95 \%$ laparotomy group).

Conclusion: Laparoscopy is safe, and has almost equal efficiency than laparotomy approach in treatment of women with early stage endometrial cancer.

\section{Keywords}

Early stage, Endometrial cancer, Laparoscopy, Laparotomy, Treatment, Pelvic lymphadenectomy

\section{Introduction}

Endometrial cancer is the most commonly reported gynecologic malignance in developed countries. Recently, endoscopic surgery has been applied for treating gynecologic malignancies. In particular, laparoscopy has been widely proposed instead of laparotomy for the treatment of women with endometrial cancer [1-3].

Compared with laparotomy, laparoscopy has been shown to be associated with many advantages such as smaller incision, better visibility of the operative field, minimal intraoperative blood loss, less postoperative pain, shorter hospital admission, and earlier return to work [1-3]. Obeseness is not a contraindication [4,5] and elderly women [6] could also benefit from laparoscopic approach.

The efficacy and safety of the laparoscopic approach to treat endometrial cancer have been established by many studies $[1,7]$ and meta-analyses $[8,9]$. These publications were performed by prestigious oncologic centers with a long period of expertise in the endoscopic field $[1,10]$, although most of them are limited to the treatment of early-stage endometrial cancer $[1,4,11]$.

Furthermore, in the last decade, several studies have demonstrated that laparoscopy is superior to laparotomy in reducing postoperative ileus, wound infec-

Citation: Eduardo GB, Lozada C (2017) Laparoscopic Versus Laparotomy Approach in Surgical Treatment of Endometrial Cancer: Pelvic Lymphadenectomy Results. Int J Womens Health Wellness 3:060. doi. org/10.23937/2474-1353/1510060

Received: August 03, 2017: Accepted: September 23, 2017: Published: September 25, 2017

Copyright: (C) 2017 Eduardo GB, et al. This is an open-access article distributed under the terms of the Creative Commons Attribution License, which permits unrestricted use, distribution, and reproduction in any medium, provided the original author and source are credited. 
tion, fever, and postoperative admission, and all these factors contribute to a reduction in morbidity $[12,13]$. However, because most studies [12,13] only followed up small groups of patients for a limited period it was difficult to properly evaluate complications, recurrence, and survival associated with laparoscopy.

The aim of our study was to compare the efficacy of a laparoscopic versus laparotomy approach in women with early stage endometrial adenocarcinoma who were followed during a period at least of 25 years.

\section{Material and Methods}

We retrospectively analyzed the medical records of all patients with endometrial adenocarcinoma who underwent a laparoscopic or open surgery for staging endometrial cancer at University Hospital Sant Joan de Deu from January 1988 to December 2013. The study was approved by the Ethics Committee. It was not possible to obtain the informed consent of all the patients due to the duration of the study.

Inclusion criteria were as follow: The presence of histopatologically confirmed endometrioid adenocarcinoma treated with standard surgical staging consisting in peritoneal washing and total hysterectomy (including both totally laparoscopic/abdominal approach and laparoscopically assisted vaginal approach) with bilateral salpingo-oophorectomy and pelvic lymphadenectomy.

Exclusion criteria were the finding of a different histological type than endometrioid adenocarcinoma, the absence of complete clinical and histological data, having not undergone a total hysterectomy or if the hysterectomy was performed vaginally.

Patient data were distinguished in the 2 groups on the basis of surgical treatment received, that is, totally laparoscopic and laparoscopically assisted vaginal approach (laparoscopy group) or laparotomy (laparotomy group).
We recorded parameters including patient age, Body Mass Index (BMI), duration of follow-up, existence of chronic disease, previous history of laparotomy, International Federation of Gynecology and Obstetrics surgical stage (FIGO 2009), tumor grade, tumor size, histopathologic type, number of lymph nodes yielded, operating time, postoperative hospital admission, perioperative and postoperative complications, conversion to laparotomy, recurrence, and survival.

Statistical analysis was performed using SPSS version 20.0. The Student t test was used to compare the mean values of continuous variables, and the $X^{2}$ test was used to compare categorical variables. To improve the normality of the skewed distributions of the continuous variables, some variables that were not normally distributed were logarithmically transformed, and then the Student $t$ test was used. Recurrence-Free Survival (RFS) and Disease-Free Survival (DFS) of the laparotomy and laparoscopy groups were obtained by the Kaplan-Meier method, and the log-rank test was used to compare survival outcomes. DFS was calculated from the date of operation of endometrial cancer to the date of death due to endometrial cancer or recurrence, whichever occurred first. Differences between groups were considered statistically significant at $P<0.05$. All $P$ values were 2-sided.

\section{Results}

Of the 282 patients who were surgically staged with endometrial cancer from January 1988 to December 2013, 3 patients were performed vaginal hysterectomy and were excluded. Of the 279 patients after inclusion/ exclusion criteria were applied, 53 patients were excluded. Thus, a total of 226 patients were analyzed, 79 patients in the Laparoscopy group (LPS) and 147 in the Laparotomy group (LPT).

Patients' characteristics are listed in Table 1. There were no significant differences in age, weight, body

Table 1: Baseline characteristics of patients.

\begin{tabular}{|c|c|c|c|}
\hline & $\begin{array}{l}\text { LPS } \$ \\
n=79\end{array}$ & $\begin{array}{l}\text { LPT" } \\
n=147\end{array}$ & $\mathbf{p}$ \\
\hline \multicolumn{4}{|l|}{ Age } \\
\hline Mean \pm SD & $60.27 \pm 9.47$ & $63.07 \pm 10.74$ & 0.052 \\
\hline Range & $36-80$ & $35-88$ & \\
\hline \multicolumn{4}{|l|}{$\mathrm{BMI}^{\mp}$} \\
\hline Mean \pm SD & $31.20 \pm 4.28$ & $32.61 \pm 4.76$ & 0.070 \\
\hline Range & 23.6-39 & $24.8-42.6$ & \\
\hline \multicolumn{4}{|l|}{ Menopause } \\
\hline Premenopause & $12(15.2 \%)$ & $22(14.6 \%)$ & 1 \\
\hline Postmenopause & $67(84.8 \%)$ & $125(85.4 \%)$ & \\
\hline \multicolumn{4}{|c|}{ Previous abdominal surgery } \\
\hline Mean \pm SD & $0.44 \pm 0.59$ & $0.37 \pm 0.49$ & 0.33 \\
\hline Range & $0-2$ & $0-3$ & \\
\hline Chronic hypertension & $34(43 \%)$ & $70(46.4 \%)$ & 0.67 \\
\hline Diabetes & $18(22.7 \%)$ & $41(27.2 \%)$ & 0.9 \\
\hline
\end{tabular}

§Laparoscopy; TLaparotomy; ${ }^{\mp}$ Body Mass Index. 
mass index, parity, previous abdominal surgery and menopausal status between the laparoscopy and the laparotomy groups. The presence of chronic disease (Chronic hypertension and Diabetes) was similar between the two groups. The grade and surgical stage was also similar between the laparoscopy and the laparotomy groups (Table 2 ).

Before surgery, a Magnetic Resonance (MR) was performed in order to evaluate the risk of miometrial, cervix or lymph node invasion. In patients with suspected invasion pelvic lymphadenectomy was performed.

Fifty eight (73.4\%) of the 79 patients and 77 (52.1\%)

Table 2: Surgical stage and grade.

\begin{tabular}{|l|l|l|l|}
\hline & $\begin{array}{l}\text { LPS } \\
\mathbf{n = 7 9}\end{array}$ & $\begin{array}{l}\text { LPT } \\
\mathbf{n = 1 4 7}\end{array}$ & $\mathbf{p}$ \\
\hline Stage (FIGO 2009), $\mathrm{n}(\%)$ & & 0.017 \\
\hline IA & $46(58.2)$ & $112(76.9)$ & \\
\hline IB & $30(38)$ & $28(19)$ & \\
\hline II & $3(3.8)$ & $7(4.7)$ & \\
\hline Total & 79 & 147 & \\
\hline Grade, $\mathrm{n}(\%)$ & & & 0.094 \\
\hline 1 & $42(53.2 \%)$ & $91(61.3)$ & \\
\hline 2 & $30(38)$ & $37(25.1)$ & \\
\hline 3 & $7(8.8)$ & $19(12.9)$ & \\
\hline Total & 79 & 151 & \\
\hline & & & \\
\hline
\end{tabular}

of the 147 patients had pelvic lymphadenectomy in the laparoscopy and the laparotomy groups, respectively, and there were no differences in the number of nodes involved between the laparoscopy and laparotomy groups $(1.7 \%$ vs. $3.8 \%$; $P=0.17)$. The mean of pelvic nodes obtained was respectively 10.7 (1-27) in the laparoscopy group and 10.6 (1-42) in laparotomy group (Table 3). There were no statistically significant differences in the numbers of nodes obtained in the laparoscopy and the laparotomy groups. The operating time was shorter in the laparotomy group (143.8 [45-265] vs. 211.5 [100-325] minutes; $P<0.001$ ). However, the postoperative hospital admission was shorter in the laparoscopy group (4.1 [2-10] vs. 7.5 [3-27] days; $\mathrm{P}<0.001$ ). More lymphadenectomy procedures were made in laparoscopic group due to higher percentage of FIGO stage IB in this group (Table 2).

There were significant differences in intraoperative or postoperative complications between the laparoscopy and the laparotomy groups $(13.9 \%$ vs. $32.5 \%$; $\mathrm{P}=$ 0.003 ) (Table 4). Seven cases of incisional hernias and 4 cases of wound dehiscences were noted in the laparotomy group, and 7 cases of conversion to laparotomy were noted in the laparoscopy group. There were 10 cases of wound infection in the laparotomy group compared with 2 in the laparoscopy group, and there were 8

Table 3: Surgical procedures and pelvic lymph nodes.

\begin{tabular}{|c|c|c|c|}
\hline & LPS $n=79$ & LPT $n=147$ & $\mathbf{p}$ \\
\hline Type of procedure, n (\%) & & & $<0.001$ \\
\hline $\mathrm{TH}^{\star}$ & $5(6.3)$ & $3(2 \%)$ & \\
\hline $\mathrm{TH}+\mathrm{BSO}^{* *}$ & $16(20.3)$ & $67(45.5)$ & \\
\hline TH + BSO + PLND & $58(73.4)$ & $77(52.3 \%)$ & \\
\hline No. of pelvic lymph nodes, $\mathrm{n}(\%)$ & & & 0.97 \\
\hline Mean \pm SD & $10.7 \pm 5.9$ & $10.67 \pm 8.6$ & \\
\hline Range & $1-27$ & $0-42$ & \\
\hline Positive lymph nodes & $1(1.7 \%)$ & $3(3.8 \%)$ & \\
\hline
\end{tabular}

*Total histerectomy; **Bilateral salpingo-oophorectomy; \#Pelvic lymph adenectomy.

Table 4: Perioperative outcomes and complications.

\begin{tabular}{|c|c|c|c|}
\hline & LPS $\mathbf{n}=79$ & LPT $n=147$ & $\mathbf{p}$ \\
\hline \multicolumn{4}{|l|}{ Operating time } \\
\hline Mean \pm SD & $211.52 \pm 52.62$ & $143.83 \pm 41.57$ & $<0.001$ \\
\hline Range & $100-325$ & $45-265$ & \\
\hline \multicolumn{4}{|l|}{ Postoperative hospital day } \\
\hline Mean \pm SD & $4.05 \pm 1.22$ & $7.54 \pm 3.32$ & $<0.001$ \\
\hline Range & $2-10$ & $3-27$ & \\
\hline Patients with complications, $\mathrm{n}(\%)$ & & & 0.003 \\
\hline Wound infection & $2(2.4)$ & $10(6.8)$ & \\
\hline Abdominal wall hematoma & $2(2.4)$ & $2(1.3)$ & \\
\hline Wound dehiscence & $0(0)$ & $4(2.7)$ & \\
\hline Postoperative ileus & $0(0)$ & $5(3.4)$ & \\
\hline Vascular injury & $1(1.2)$ & $3(2)$ & \\
\hline Intestinal injury & $1(1.2)$ & $2(1.3)$ & \\
\hline Urinary tract injury & $2(2.4)$ & $4(2.7)$ & \\
\hline Incisional hernia & $2(2.4)$ & $7(4.7)$ & \\
\hline Hemoperitoneum & $0(0)$ & $4(2.7)$ & \\
\hline Urinary tract infection & $1(1.2)$ & $8(5.4)$ & \\
\hline Total & $11(13.9)$ & 49 (33.3) & \\
\hline
\end{tabular}


Table 5: Recurrence and survival outcomes.

\begin{tabular}{|l|l|l|l|}
\hline & LPS & LPT & $\mathbf{p}$ \\
$\mathbf{n = 7 9}$ & $\mathbf{n = 1 4 7}$ & \\
\hline Recurrence, $\mathrm{n}(\%)$ & $1(1.2)$ & $9(5.9)$ & 0.099 \\
\hline 5 years recurrence-free survival (\%) & $98 \%$ & $94 \%$ & 0.3 \\
\hline 5 years overall survival rates (\%) & $100 \%$ & $95 \%$ & 0.4 \\
\hline
\end{tabular}

cases of urinary tract infection in the laparotomy group compared with 1 case in the laparoscopy group.

Adjuvant therapy was radiotherapy (brachytherapy or/and external radiotherapy). This treatment did not differ in both groups, and it was applied in case of deep miometrial invasion, grade 3 tumors, cervix involvement or nodes metastases.

One patient in the laparoscopy group (1.2\%) and 8 patients in the laparotomy group (5.5\%) had recurrence of the disease; this difference was not statistically significant $(P=0.099$; Table 5).

Women who underwent laparoscopy and those who underwent laparotomy had similar 5 years estimated recurrence-free survival rates $(98 \%$ vs. $94 \%$ respectively) as well as similar 5 years overall survival rates $(100 \%$ vs. $95 \%$ respectively) (Table 5 ).

\section{Discussion}

Surgical treatment of endometrial cancer has been traditionally performed by laparotomy approach to accomplish a Total Abdominal Hysterectomy (TAH) and of retroperitoneal lymph nodes staging [14]. Childers and Surwit [15] were the first authors to report the use of Laparoscopically Assisted Vaginal Hysterectomy (LAVH) with laparoscopic staging of pelvic and paraaortic lymph nodes in 1992 for treatment of early-stage endometrial cancer. Since that time, numerous authors have reported their institutional experience with laparoscopic surgery for endometrial cancer [16-18].

Our present study with 226 patients with endometrial cancer followed over the long period of 25 years provides significant information about the efficacy and complications of patients with endometrioid cancer histological type and stage I and II FIGO 2009 who underwent surgery.

In the present study, there were no significant differences between 2 groups (LPS vs. LPT) in the grade of the tumor and FIGO stage of endometrial cancer (Table 2). Although several studies $[14,19,20]$ have suggested that the grade of the tumor and the histological type could draw the indication for the surgical approach. In our study, the surgical approach was not influenced by the grade of the tumor.

As expected, in the current analysis, patients with endometrial cancer higher than stage I were more likely to undergo laparotomy without being a statistically significant difference. However, in about $4 \%$ of endometrial cancers with FIGO stage II of our study, the laparoscopy approach was performed, and in all of them, it was successfully concluded without conversion to laparotomy.

In our study the percentage of patients with pelvic lymphadenectomy was similar in laparoscopy and laparotomy group (73.4\% vs. $52.1 \%$ respectively) other studies with larger number of patients had a few patients with lymphadenectomy in laparoscopic group (16\% vs. 45\%) [21]. Percentage of positive pelvic lymph nodes was very low in both groups 1.7 and $3.8 \%$ respectively, in all the cases risk factor for lymph nodes metastases were present (deep miometrial invasion, G3 and lymphovascular space involvement) [22]. In our study we only perform pelvic lymphdenectomy in women with an early stage endometrial carcinoma and endometrioid histology because, only $2 \%$ of patients with negative pelvic lymph nodes had positive paraortic [23] and when techniques for detecting sentinel lymph node are used in endometrial cancer staging most of the lymph nodes detected are situated into the pelvis [24].

Some studies [25] observed a similar duration of surgery performed laparoscopy or laparotomy, in our case laparoscopy group had significant long operating time than laparotomy group although the surgical period was shorter after the first cases (surgeon learning curve).

We conclude as other studies $[14,26]$ that there is no difference in overall survival in patients with endometrial cancer treated by laparoscopy or laparotomy in early FIGO (stage I or II). Adjuvant therapy with radiotherapy does not affect to overall survival of both groups as we see in other studies of the literature $[27,28]$.

Laparoscopy group benefits from less complication associated with surgery, shorter hospital admission and earlier recovery. Laparoscopy is safe, and has almost equal efficiency than laparotomy approach in treatment of women with early stage endometrial cancer.

One of the weaknesses of the study is the retrospective nature; randomized studies with larger number of patients are needed to confirm our results.

\section{Disclosure}

All the authors declare that there are not any financial or personal relationships with other people or organizations that could inappropriately influence (bias) our work.

\section{References}

1. Zullo F, Palomba S, Russo T, Falbo A, Costantino M, et al. (2005) A prospective randomized comparison between laparoscopic and laparotomic approaches in women with early stage endometrial cancer: a focus on the quality of life. Am J Obstet Gynecol 193: 1344-1352.

2. Magrina JF, Mutone NF, Weaver AL, Magtibay PM, Fowler RS, et al. (1999) Laparoscopic lymphadenectomy and vaginal or laparoscopic hysterectomy with bilateral salpingo-oophorectomy for endometrial cancer: morbidity and survival. Am J Obstet Gynecol 181: 376-381. 
3. Lim BK, Lavie O, Bolger B, Lopes T, Monaghan JM (2000) The role of laparoscopic surgery in the management of endometrial cancer. BJOG 107: 24-27.

4. Tozzi R, Malur S, Koehler C, Schneider A (2005) Laparoscopy versus laparotomy in endometrial cancer: first analysis of survival of a randomized prospective study. J Minim Invasive Gynecol 12: 130-136.

5. Scribner DR Jr, Walker JL, Johnson GA, McMeekin DS, Gold MA, et al. (2002) Laparoscopic pelvic and paraaortic lymph node dissection in the obese. Gynecol Oncol 84: 426-430.

6. Scribner DR Jr, Walker JL, Johnson GA, McMeekin SD, Gold MA, et al. (2001) Surgical management of early stage endometrial cancer in the elderly: is laparoscopy feasible? Gynecol Oncol 83: 563-568.

7. Walker JL, Piedmonte MR, Spirtos NM, Eisenkop SM, Schlaerth JB, et al. (2009) Laparoscopy compared with laparotomy for comprehensive surgical staging of uterine cancer: Gynecologic Oncology Group Study LAP2. J Clin Oncol 27: 5331-5336.

8. Palomba S, Falbo A, Mocciaro R, Russo T, Zullo F (2009) Laparoscopic treatment for endometrial cancer: a meta-analysis of randomized controlled trials (RCTs). Gynecol Oncol 112: 415-421.

9. Palomba S, Falbo A, Russo T, Zullo F (2009) Updating of a recent meta-analysis of randomized controlled trials to assess the safety and the efficacy of the laparoscopic surgery for treating early stage endometrial cancer. Gynecol Oncol 114: 135-136.

10. Janda M, Gebski V, Brand A, Hogg R, Jobling TW, et al. (2010) Quality of life after total laparoscopic hysterectomy versus total abdominal hysterectomy for stage I endometrial cancer (LACE): a randomised trial. Lancet Oncol 11: 772-780.

11. Mourits MJ, Bijen CB, Arts HJ, terBrugge HG, van der Sijde $R$, et al. (2010) Safety of laparoscopy versus laparotomy in early-stage endometrial cancer: a randomised trial. Lancet Oncol 11: 763-771.

12. Jeon YT, Song YS (2004) Novel therapeutic strategies for uterine endometrial cancer. Cancer Res Treat 36: S66-S68.

13. Kalogiannidis I, Lambrechts S, Amant F, Neven P, Van Gorp T, et al. (2007) Laparoscopy-assisted vaginal hysterectomy compared with abdominal hysterectomy in clinical stage I endometrial cancer: safety, recurrence, and longterm outcome. Am J Obstet Gynecol 196: 248.e1-248.e8.

14. Leiserowitz Gary, Xing Guibo, Parikh-Patel Arti, Cress Rosemary, Abidi Alireza, et al. (2009) Laparoscopic Versus Abdominal Hysterectomy for Endometrial Cancer Comparison of Patients Outcomes. Int J Gynecol Cancer 19: 13701376.
15. Childers JM, Surwit EA (1992) Combined laparoscopic and vaginal surgery for the management of two cases of stage I endometrial cancer. Gynecol Oncol 45: 46-51.

16. Magrina JF (2005) Outcomes of laparoscopic treatment for endometrial cancer. Curr Opin Obstet Gynecol 17: 343-346.

17. Fram KM (2002) Laparoscopically assisted vaginal hysterectomy versus abdominal hysterectomy in stage I endometrial cancer. Int J Gynecol Cancer 12: 57-61.

18. Holub Z, Jabor A, Bartos P, Eim J, Urbánek S, et al. (2002) Laparoscopic surgery for endometrial cancer: long-term results of a multicentric study. Eur J Gynaecol Oncol 23: 305-310.

19. Hahn H, Kim H, Yoon S, Yoon SG, Kim WC, et al. (2010) Laparoscopic-assisted vaginal versus abdominal hysterectomy in endometrial cancer. Int J Gynecol Cancer 20: 102-109.

20. Palomba S, Ghezzi F, Falbo A, Mandato VD, Annunziata G, et al. (2012) Laparoscopic versus abdominal approach to endometrial cancer: A 10-year retrospective multicenter analysis. Int J Gynecol Cancer 22: 425-433.

21. Eltabbakh GH (2002) Analysis of survival after laparoscopy in women with endometrial carcinoma. Cancer 95: 1894-1901.

22. Muallem MZ, Sehouli J, Almuheimid J, Richter R, Joukhadar R, et al. (2016) Risk factors of lymph nodes metastases by endometrial cancer: A retrospective one-center study. Anticancer Research 36: 4219-4225.

23. MarianiA, Keeney GL, Aletti G, Webb MJ, Haddock MG, et al. (2004) Endometrial carcinoma: paraaortic dissemination. Gynecol Oncol 92: 833-838.

24. Papadia A, Imboden S, Siegenthaler F, Gasparri ML, Mohr S, et al. (2016) Laparoscopic Indocyanine Green Sentinel Lymph Node Mapping in Endometrial Cancer. Ann Surg Oncol 23: 2206-2211.

25. Malur S, Possover M, Michels W, Schneider A (2001) Laparoscopic-assisted vaginal versus abdominal surgery in patients with endometrial cancer-a prospective randomized trial. Gynecol Oncol 80: 239-244.

26. Lee CL, Kusunoki S, Huang KG, Wu KY, Huang CY, et al. (2016) Long-term survival outcomes of laparoscopic staging surgery in treating endometrial cancer: 20 years of follow-up. Taiwan J Obstet Gynecol 55: 545-551.

27. Latif NA, Haggerty A, Jean S, Lin L, Ko E (2014) Adjuvant therapy in early-stage endometrial cancer: a systematic review of the evidence, guidelines, and clinical practice in the U.S. Oncologist 19: 645-653.

28. Creutzberg CL, van Putten WL, Koper PC, Lybeert ML, Jopsen JJ, et al. (2000) Surgery and post operative radiotherapy versus surgery alone for patients with stage-1 endometrial carcinoma: Multi centre randomised trial. PORTEC Study Group. Post Operative Radiation Therapy in Endometrial Carcinoma. Lancet 355: 1404-1411. 